\title{
Establishing the Relationship between Teacher Efficacy and Malaysian Primary Pupils' Achievement in Formative Reading Assessment
}

\author{
Manoranjini Sandaraj, Harwati Hashim \\ Faculty of Education, Universiti Kebangsaan Malaysia, Bangi, Malaysia \\ Email:harwati@ukm.edu.my
}

How to cite this paper: Sandaraj, M., \& Hashim, H. (2022). Establishing the Relationship between Teacher Efficacy and Malaysian Primary Pupils' Achievement in Formative Reading Assessment. Creative Education, 13, 491-503.

https://doi.org/10.4236/ce.2022.132029

Received: December 29, 2021

Accepted: February 14, 2022

Published: February 17, 2022

Copyright $\odot 2022$ by author(s) and Scientific Research Publishing Inc. This work is licensed under the Creative Commons Attribution International License (CC BY 4.0).

http://creativecommons.org/licenses/by/4.0/

\begin{abstract}
The presence of qualified teachers in the Education scenario ensures that the targeted academic achievement is duly met at primary school level. Thus, it is vital that Malaysian English teachers are aware of their self-efficacy that projects their inner motivation, behaviour and social planning in order to achieve academic excellence among pupils. The aim of this study is to mainly focus upon primary school teachers' self-efficacy and the effect on English formative-reading assessment of pupils. In this study, a quantitative research method has been used. About 30 samples were selected mainly from primary school English teachers in a school in Selangor and 90 Year 5 pupils were selected randomly. Teacher self-efficacy questionnaires for teachers were utilised to collect data and to analyse pupils' reading achievement and their formative reading assessment marks were used. Pearson Correlation and Multiple Regressions were used in analysing the collected data. The findings suggested that teachers with higher self-efficacy are more likely to be motivated and committed to ensure better reading achievement among pupils. The discussion of the results pertaining to the findings as well as recommendations and limitations are provided for future research.
\end{abstract}

\section{Keywords}

Assessment, Correlation, Malaysian Primary School Students, Reading Assessment, Teacher Efficacy

\section{Introduction}

The present condition within the education world revolves around constant new directives that may seem very demanding to many who are serving interminably 
and loyally. Nevertheless, the constant change in the education system may challenge teachers' self-efficacy. Job-satisfied teachers may work towards delivering their best performance by managing, organizing, and performing specific tasks at the highest excellence, even when students' academic performance may not fit the effort spent (Gkolia et al., 2014). This is because teacher efficacy is directly linked to one's personal motivation to execute positive plans to ensure pupils achieve targeted goals. Their self-efficacy enables them to implement new strategies within their teaching zone to ensure students develop and produce positive academic achievement (Katz, Dack, Malloy, \& Ontario Principals' Council, 2018). Meanwhile, Bandura (2002) explains that a high-level efficacy among teachers ensures their ability to execute actions according to the plans of ensuring certain goals that are met. Besides that, a high level of efficacy among teachers projects a positive outlook towards everything, especially in terms of having good two-way communication with students. They are also more accepting and are capable of new methods and techniques to ensure goals are met. These teachers also will adhere to new ever-changing rules in the execution of the plans by the Education Ministry to ensure better achievement among pupils.

This scenario reflects the present global situation since teachers adapt to teaching online, inducing creativity in teaching methods. In the past, the teachers were merely teaching physically in the classroom.

Presently due to the pandemic outburst teachers adhered to the Malaysian Education Plan to fully conduct online lessons from March - August 2020, then June - November 2021. According to Gul (2014), students need to be taught additional skills such as decision making, being analytical, having a balanced mindset, to ensure students are capable to strive both during academic and in professional life. To meet these phases in students' life, teachers should be aware of self-efficacy for the pursuit to complete the given tasks successfully. Teachers would be able to ensure better academic results among pupils. According to Bandura (1977), improved teacher self-efficacy results in enhanced teacher mental health and job satisfaction as well as students' academic results. Based upon the above-mentioned points, this study was conducted to identify the impact of teacher self-efficacy on the primary pupils' achievement in formative reading assessment.

Many teachers are not aware of their self-efficacy skills (Barni et al., 2019), causing pupils' state of lagging far behind since teachers do not attempt to apply new teaching strategies, especially when there are obvious low achievers among pupils. This study explored the impacts of teacher self-efficacy on pupils' English reading achievement. As such, this study was structured based upon three hypotheses:

H1: There is a significant relationship between teacher self-efficacy and pupils' formative reading assessment.

$\mathrm{H} 2$ : There is a significant relationship between teacher self-efficacy belief regarding pupils' engagement and pupils' formative reading assessment. 
H3: There is a significant relationship between teacher self-efficacy belief regarding instructional strategies and pupils' formative reading assessment.

\section{Literature Review}

\subsection{Self-Efficacy and Its Components in Social Cognitive Theory}

The idea of self-efficacy was introduced by Bandura through his social-cognitive theory of behavioural change where an individual's aspiration to achieve a certain level of achievement and success is identified as self-efficacy (Bandura, 1977). According to social cognitive theory, it is a channel that contributes to decision-making to intentionally follow to meet targeted success or outcome. In a scenario whereby teachers are motivated to create necessary teaching materials for a lesson to ensure pupils' understanding towards better lessons displays teachers' perception of self-efficacy in producing targeted results. Thus, beliefs of self-efficacy simply explain the plans that teachers make and execute about their teaching behaviour to ensure certain targets are made. Teachers who possess better self-efficacy ensure their capacity to withstand distressful moments, ensuring their thoughts are productive and attaining the desired objective and outcome. High self-efficacy encourages human accomplishment and personal well-being (Bandura, 1994). People with high affirmation in their own capacity will address difficult tasks with a positive outlook, which is to master the challenges ahead, instead of avoiding them. Additionally, it can be said that teachers of high self-efficacy in a school are a productive asset as they would strive and go the extra mile to ensure desired aspirations of an institution are met.

Bandura (1977) lists 4 main sources of influence of self-efficacy which are vital for teachers: 1) personal experience, 2) vicarious experience, 3) social persuasion or positive encouragement and appraisal, and 4) physiological and emotional behaviours. In personal experience, teachers share their experiences which then become personal accomplishments (or personal efficacy), which requires sustained efforts needed after many trials and tribulations. A person with easy success would be discouraged when faced with problems, unlike a stronger individual growth that reflects his strength (Bandura, 1977). Secondly, the vicarious experience which is the ability to learn from others' experiences. This ability to model after others, especially the success of others helps build towards a positive attitude and encourages better performance. Thirdly, the combination of social persuasion, positive encouragement, and appraisal also helps encourage better performance. As such, encouragement, support, and recognition from the administrator as well as society are likely to boost confidence, thus helping teachers to project a positive attitude towards self-efficacy. Finally, the fourth aspect is the physiological and emotional behaviours where a confident and energetic person will display positive outcomes while a pessimistic and negative opinionated individual will produce negative results (Bandura, 1977). In the case of teachers, academic qualification does not ensure excellence but confidence will boost their strategies that ensure academic achievement. Accumulated experience helps plan 
towards improved teaching methods and techniques in delivering better lessons in the classroom.

\subsection{Relation between Teacher Efficacy and Academic Achievement}

Numerous studies mainly reiterate Bandura's proposition that efficacy beliefs motivate individual planning towards better performance to achieve targeted goals (Mahler et al., 2018; Dari et al., 2021; Aytaç, 2021). In fact, there is evidence that teacher efficacy is directly linked to academic achievement and a high level of teacher efficacy fosters better academic achievement among students. Kim and Seo's (2018) research on 4130 teachers, support the correlation between teacher efficacy and academic achievement. They find that the mean relationship between teacher efficacy and students' academic achievement is significant. Alibakhshi et al. (2020) confirmed that teachers' self-efficacy significantly contributed to students' academic achievement, especially speaking because teachers with high efficacy held positive attitudes and worked to ensure friendly relationships with students. In another research using data gained from teacher interviews and questionnaire responses, Bal-Taştan et al. (2018) look into the impacts of teacher efficacy on students' motivation on academic performance, particularly science education in secondary schools in Iran and Russia.

The findings supported the idea that there are significant impacts of teacher self-efficacy and motivation on academic achievement in science education. In another direction, it was found that teachers with high efficacy levels also demonstrate a high level of creativity during challenging times. Cayirdag (2017) and Li et al. (2017) show highly-motivated teachers to help inculcate creativity among their students, thus indicating that proactive teachers not only display high efficacy but innovate teaching materials to ensure their students' achievement. Mahasneh and Alwan (2018) investigated the effects of project-based learning on trainee teachers' self-efficacy and achievement where they are more active, creative, and focused, leading towards more active student participation and better academic performance.

\subsection{Malaysian Primary School Reading Assessment}

The Ministry of Education Malaysia (MOE) in the Malaysian Education Blueprint 2013-2025, has outlined methods to assess pupils' language ability where the most important areas of language learning are evaluated and measured. The four language skills in English (Listening, Speaking, Reading, and Writing) are taught and assessed periodically to ensure pupils' progress is recorded for assessment. These skills are blended in the lesson and taught separately where each is combined into the areas of the lesson taught. At the end of the lesson, pupils will communicate, by not only conversing and listening to each other but also responding to one another by writing messages and letters. This combined approach in assessing language use and competence gives the pupils the freedom of space to demonstrate their communicative ability. MOE strongly believes pupils 
should be graded for their use of language, instead of mere grading of written examinations. Lim et al. (2018) validate the assessment procedures planned by MOE that provide thorough and consistent information regarding the pupils reading progress, others are looking at unachieved reading objectives when students read literature Mohaideen et al. (2020), thus challenging the validity of such assessment. Teachers administered planned assessments should be able to document the pupils' strengths and weaknesses, which in return would help the teachers with the necessary strategies to guide the pupils for better achievement. Sidhu, Kaur and Chi (2018) suggested that teachers are aware of the method of assessment and with a lack of knowledge regarding the method of assessment can be coached over time. In general, all the study shows that primary school teachers are aware of the present reading assessment method.

\section{Methodology}

\subsection{Research Design}

Data collection, data analysis, and report writing are the main procedures in research design Creswell (2012). The study was carried out using the quantitative research method to derive the necessary data pertaining to teacher efficacy and pupils reading achievement. There is one dependent variable which pupils read formative assessment scores and 2 dependent variables. A quantitative research design was adopted for this study as it allows better representation to derive the necessary data Creswell (2012). Thus, the research design of this study will help meet the main objective of this study which is a correlational study that relates two variables between teachers' self-efficacy and pupils' reading achievement.

\subsection{Population and Sample}

The population of this study includes male and female primary teachers as well as male and female Year 5 pupils of a school in Selangor, Malaysia. 30 teachers $(\mathrm{M}=6 ; \mathrm{F}=24)$ were selected while 90 pupils were selected as participants. $3 \mathrm{pu}$ pils were assigned to 1 teacher to tabulate the former's reading achievement as suggested by Creswell (2014) where educational research such as this only requires approximately 30 participants for a correlational study that relates variables.

From the 30 teacher samples, 13 of them were between the age of 31 - 26 years old and 10 between the ages of $42-47$. As indicated in Table 1, only 5 teachers are considered novice teachers (age between 25 - 30) and 2 between the ages of 48 - 53 years old.

Meanwhile Table 2 indicates the respondents' teaching English experience in primary schools. The majority of the respondents (43.3\%) have $11-20$ years of experience in teaching English in primary schools, while 10\% have less than 10 years of teaching experience. A longer experience ensures teachers with certain confirmed classroom practices and experiences that support increased reading achievement among pupils. 
Table 1. Frequency and percentage of the teachers age.

\begin{tabular}{ccc}
\hline Age & Frequency & Percentage \\
\hline $25-30$ & 5 & $16 \%$ \\
$31-36$ & 13 & $43 \%$ \\
$37-42$ & 10 & $33 \%$ \\
$43-48$ & 1 & $4 \%$ \\
$49-54$ & 1 & $4 \%$ \\
Total & 30 & 100 \\
\hline
\end{tabular}

Table 2. Frequency and percentage of the teachers' experience.

\begin{tabular}{ccc}
\hline Teaching Experience & Frequency & Percentage \\
\hline $1-10$ years & 3 & 10.0 \\
$11-20$ years & 13 & 43.3 \\
$21-30$ years & 13 & 43.3 \\
More than 30 years & 1 & 3.3 \\
Total & 30 & 100.0 \\
\hline
\end{tabular}

\subsection{Research Instrument}

Tschannen-Moran and Hoy's (2001) The Teacher Self-efficacy Scale (TSES) was used for this study since it enables effective data collection of teacher self-efficacy (Shahzad \& Naureen, 2017; Chen \& Yang, 2019; Barni et al., 2019). Different experts were referred in order to validate the instrument; their suggestions were then taken into consideration before using the instrument. There are three subscales and 24 questions in this questionnaire, which are distributed to answer aspects regarding classroom management (8 questions), instructional strategies (8 questions) and student engagement (8 questions) in relation to teacher self-efficacy. Instead of employing a 9-points Likert scale, which are mainly made up of Nothing, Very Little, Some Influence, Quite a Bit, and A Great Deal, the adopted version used a 5-points Likert scale from 1 - Nothing to 5 - A great Deal to help respondents answer easily. The overall reliability (Cronbach Alpha) of the instrument was .94 .

\subsection{Data Collection Procedure and Data Collection Analysis}

Data were collected through survey as well as from each teacher's scores on the TSES survey. The survey data represents the teachers' score on the short version of the Teacher's Sense of Efficacy Scale. The short form was chosen because respondents were teachers in service (Tschannen-Moran et al., 1998). Due to the current pandemic situation, participants answered the instrument through Google Form. The participants took approximately 3 - 5 minutes to complete at their own time and space. In order to derive the reading assessment score of the 
pupils, the teachers gave the scores of the reading achievement of the second assessment conducted in the month of October.

In order to analyse the data, IBM SPSS (version 26) was utilized to calculate the Pearson correlation coefficient and multiple regression to test on the hypotheses.

\section{Analysis and Discussion}

This section is divided in order to answer the research objective (to explore the impacts of teacher self-efficacy on pupils' English reading achievement) and to test the three hypotheses:

H1: There is a significant relationship between teacher self-efficacy and pupils' formative reading assessment.

H2: There is a significant relationship between teacher self-efficacy belief regarding pupils' engagement and pupils formative reading assessment.

H3: There is a significant relationship between teacher self-efficacy belief regarding instructional strategies and pupils' formative reading assessment.

\subsection{Teacher Self-Efficacy and Pupils Reading Assessment Achievement}

Table 3 clearly reflects the overall mean score and standard deviation of the teacher's self-efficacy. The means score 3.83 ( $\mathrm{SD}=.747$ ) indicates positive perceptions of the respondents about teacher self-efficacy. Teachers with self-efficacy are teachers who are motivated and are always planning lessons creatively to cater to the needs of the pupil's learning ability.

The overall findings obtained from this research show that there is a positive relationship between teacher self-efficacy and pupils' reading assessment achievement. This shows that the previous findings by other researchers are on par with this study. The findings simply translate that the higher the teachers 'self-efficacy the better the pupils will achieve in reading assessment. The positive nuances portrayed by the teachers will have a positive outcome from the pupils. The findings also support the idea that there is a positive correlation between the dependent and independent variables, which accepts the first hypothesis as suggested in this study: There is a significant relationship between teacher self-efficacy (TSE) and pupils' reading assessment achievement. In a study conducted by Tschannen \& Woolfolk (2001) among 410 teachers have concluded that the instrument is valid to assess efficacy among teachers. Thus, the above findings of this study support the idea that there is a positive correlation between teacher self-efficacy and formative reading assessment achievement.

Table 3. Overall perception of teachers regarding self-efficacy.

\begin{tabular}{ccc}
\hline Descriptive Statistics & Mean & Std. Deviation \\
\hline Feedback of the respondents about Self-efficacy & 3.83 & .747 \\
\hline
\end{tabular}




\subsection{Relationships between Teacher Self-Efficacy Belief Regarding Pupils' Engagement and Pupils Reading Assessment Achievement}

Table 4 shows the correlation between teacher self-efficacy and reading assessment achievement of the pupils. There is a positive relationship between teacher self-efficacy $(M=3.83, \mathrm{SD}=.747)$ and pupils reading achievement $(\mathrm{M}=4.01, \mathrm{SD}$ $=.772), \mathrm{r}=.333, p \leq .05, \mathrm{n}=30$. The results show that there is a correlation (.333) between teacher self-efficacy and reading assessment achievement of the pupils. This clearly proves that teachers who are motivated will be proactive in planning lessons that will ensure better reading assessment achievement among pupils.

Self-efficacy is about planning and executing positive tasks to derive expected outcomes. Highly motivated teachers project a high form of self-efficacy, thus influencing their individual performances. Composed, controlled and good at problem solving teachers are better at guiding pupils when they do not meet the required passing marks. As teachers are confident, they also impart the confidence to the other teachers as well as their pupils.

In reference to the first hypothesis of this study, which is to see the relation between teacher's self-efficacy and pupils reading assessment achievement, many findings have proven that there is positive correlation (Shahzad \& Naureen, 2017; Bal-Taştan et al., 2018). Thus, supporting the findings of this study particularly the positive correlation between teacher's self-efficacy and reading assessment achievement. Tschannen \& Woolfolk (2001) further supported that the findings in their study reflected teacher's abilities to ensure the pupils achieve the particular goal set particularly among pupils who are low achievers

\subsection{Relationship between Teacher Self-Efficacy Belief Regarding Pupils' Engagement and Pupils Reading Assessment Achievement}

This research was able to prove the hypothesis that there is a significant relationship between teacher self-efficacy regarding pupils' engagement and pupils' reading assessment achievement. Table 5 explains the correlation between

Table 4. Correlation between teacher self-efficacy and pupils reading assessment achievement.

\begin{tabular}{cccccc}
\hline Variable & N & M & SD & Sig. (2-tailed) & R \\
\hline Teachers Self efficacy & 30 & 3.83 & .747 & .072 & .333 \\
Pupils Assessment achievement & 90 & 4.01 & .772 & & \\
\hline
\end{tabular}

Table 5. Correlation between teacher self-efficacy belief regarding pupils' engagement and pupils reading assessment achievement.

\begin{tabular}{cccccc}
\hline Variable & N & M & SD & Sig. (2-tailed) & R \\
\hline $\begin{array}{c}\text { Teachers Self efficacy regarding } \\
\text { engagement }\end{array}$ & 30 & 3.53 & .860 & .167 & .259 \\
$\begin{array}{c}\text { Pupils Assessment achievement } \\
\text { Put }\end{array}$ & 90 & 4.01 & .772 & & \\
\hline
\end{tabular}


teacher self-efficacy belief regarding pupils' engagement and pupils reading assessment achievement. There is a positive relationship between teacher self-efficacy $(\mathrm{M}=3.53, \mathrm{SD}=.860)$ and reading assessment achievement $(\mathrm{M}=4.01, \mathrm{SD}=.772), \mathrm{r}$ $=.259, p \leq .05, \mathrm{n}=30$. The results convey the idea that there is a correlation (.259) between teacher self-efficacy belief regarding pupils' engagement and pupils reading assessment achievement.

Table 6 clearly shows that there is a positive and significant correlation between both variables. Teachers will have to plan reading lessons that are attention engaging especially among primary pupils. The reading lesson should have a variety of activities such as a reading aloud session, questions and answer session to ensure pupils are engaged in the session. Besides that, teachers also should incorporate individual and group work during the reading lesson. This is to ensure pupils participate actively in the lesson, by doing so pupils will be able to learn to read English better.

Hashim et al. (2018) in a study revealed that many types of learning reading strategies were applied by undergraduates to learn English. These strategies are adopted by learners to ensure they will be able to communicate and use the language proficiently. The quantitative study among 10 respondents was conducted among adult learners. In the context of young learners such as in primary schools, English teachers play an important role to introduce the variety of strategies to allow the learners the opportunity to be aware of the variety of strategies that can be applied to master the language at a younger age. As young learners are keen to use different strategies in combination, teachers should identify the factors that influence the strategy used by their pupils as suggested by Sani and Ismail (2021). Thus, Tschannen \& Woolfolk (2001) stated that higher efficacy among teachers enables them to be more supportive and does not criticize pupils' shortcomings especially when mistakes are made. Teachers would apply appropriate instructional strategies to help the low achievers and will always use positive strategies such as praises and rewards to ensure pupils do well.

This study also explains that teachers will try to motivate the most difficult pupils in the class to achieve the desired target, provided they are not having any learning disabilities such as autism, dyscalculia, dyslexia or any other form of learning difficulties. Thus, it is safe to state that the experiences throughout the research confirms the idea that teacher self-efficacy has significant positive influence on pupils' reading achievement.

Table 6. Correlation between teacher self-efficacy belief regarding instructional strategies and pupils reading assessment achievement.

\begin{tabular}{cccccc}
\hline Variable & N & M & SD & Sig. (2-tailed) & R \\
\hline $\begin{array}{c}\text { Teachers Self efficacy regarding } \\
\text { instructional strategies }\end{array}$ & 30 & 4.13 & .937 & .576 & .106 \\
$\begin{array}{c}\text { Pupils Assessment achievement } \\
\text { Punen }\end{array}$ & 90 & 4.01 & .772 & & \\
\hline
\end{tabular}




\subsection{Relationship between Teacher Self-Efficacy Belief Regarding Instructional Strategies and Pupils' Reading Assessment Achievement}

In order to prove the third hypothesis, which is There is a significant relationship between teacher self-efficacy belief regarding instructional strategies and pupils' reading assessment achievement, Table 6 explains the relationship between teacher self-efficacy belief regarding instructional strategies and pupils' reading assessment achievement. There is a positive relationship between instructional strategies of teacher self-efficacy beliefs $(M=4.13, \mathrm{SD}=.937)$ and pupils' reading assessment achievement $(\mathrm{M}=4.01, \mathrm{SD}=.772), \mathrm{r}=.106, p \leq .05$, $\mathrm{n}=30$.

The results show that there is a correlation (.106) between the two variables. Teachers with high self-efficacy will work towards implementing alternative instructional strategies to ensure better reading achievement among the pupils. Teachers will plan better reading lessons as a preparation for pupils to achieve better in assessment.

The findings also showed that teachers with self-efficacy will strife to improve the achievement of the pupils. Teachers with more self-efficacy will work directly to improve the achievement of the pupils. Teachers will be observant of their pupils through their observation in the classroom. All such criteria clearly state that teacher self-efficacy has greater impact in the development of the pupils.

This positive correlation proves Tschannen \& Woolfolk (2001) idea that higher efficacy teachers will have greater level of planning and organization as well as be open to new ideas and they are willing to experiment any new suggestion to ensure academic excellence among the pupils. Teachers will plan for example game-based learning sessions during English lessons to ensure pupils are motivated and enjoy learning English the fun way. Moreover, English lessons in primary school should be filled with a variety of language games to ensure more active, energetic, enjoyable, student-centred learning takes place as suggested by Rajendran et al. (2019) in a study which involved pupils from a rural area in Melaka.

\section{Conclusion and Recommendations}

This research showed a significant positive relationship between teacher self-efficacy and the pupils' reading assessment achievement. Teachers' clear portrayal of a high level of efficacy encourages pupils to strive better, causing better results, particularly in pupils reading assessment. Not only these teachers would go through great lengths to understand the root cause of their pupils' inability to read well, but also apply necessary interventions to upgrade the pupils' reading ability. Besides that, in a study, it revealed that reading lessons are important to further enable pupils to write better, so reading activities should be conducted well at primary level as reading influences writing. Although numerous studies have reflected teacher self-efficacy beliefs on academic achievement, perform- 
ance and success of the students in their educational results which involves older students and higher learning institutions, more studies should proceed at understanding the correlation of teachers' self-efficacy and English reading achievement among the lower primary pupils of Year 1 to Year 3. Since this study was unable to physically meet the respondents due to the pandemic where it could have been expanded to include the lower-level primary teachers who endure more challenges, future research may also look into expanding on both private and public learning institutions.

This research also sees the relevance of suggesting a list of recommendations. For one, there should be more training programmes for the teachers to improve their personal level of self-efficacy. This would allow the teachers to impart the same knowledge unto their pupils once they are in service. Besides that, the Education Ministry should select only candidates who have passed pre-entry examination as a selection prerequisite. This would help filter candidates who choose a teaching career as an easy option to enter into tertiary education. The candidates should be chosen, because they are passionate about the career. This would help instil and sustain the desire to stay as highly motivated teachers naturally, who would have high confidence in teaching abilities particularly teaching English. Highly motivated teachers will look into any given directives to attend courses suggested by The Ministry of Education for upgrading as an opportunity to exchange views, share thoughts, expand knowledge and experiences to teach English in the 21st century better aside from upgrading their personal English competency. Most importantly, the Education Ministry should plan and organize any directives well, to ensure the in-service teachers do not feel pressured and unmotivated to perform their teaching duty well. More emphasis should be given for teaching than other secondary duties.

At the school administration level, scaffolding and necessary support should be given all the time. Teachers should always have a mentor, a senior and experienced teacher to guide and share their experiences. Besides that, using technology enhances better English learning particularly among primary school learners, thus teachers who would require assistance to handle digital tools need mentor to assist. Every teacher should be given an opportunity to exhibit their talent. They should be assigned to exhibit their capacity handling challenging responsibilities. This would allow them to introduce routines in the school monitored by them. School routines will ensure all the pupils participate actively to learn the English language actively. This will ensure effort and enthusiasm, as well as motivation to be an excellent teacher with high efficacy to complete given work. Constant group training among the teachers will also fuel proactive collective behaviours, feelings, thoughts, and motivations, since collective efficacy is a social resource that does not get reduced by its use and only encourages better performances in the future, especially mentor assistance for teachers who are in need of help and assistance. Helping and guiding from the early stages of the service would encourage new teachers in the service to perform better and help 
create a valuable support system in the coming years of challenging tenure as a teacher.

\section{Acknowledgements}

The authors would like to acknowledge Universiti Kebangsaan Malaysia under the Research Grant number 1) GG-2021-003 and 2) GG-2020-027 for supporting this project.

\section{Conflicts of Interest}

The authors declare no conflicts of interest regarding the publication of this paper.

\section{References}

Alibakhshi, G., Nikdel, F., \& Labbafi, A. (2020). Exploring the Consequences of Teachers' Self-Efficacy: A Case of Teachers of English as a Foreign Language. Asian-Pacific Journal of Second and Foreign Language Education, 5, Article No. 23. https://doi.org/10.1186/s40862-020-00102-1

Aytaç, A. (2021). A Study of Teachers' Self-Efficacy Beliefs, Motivation to Teach, and Curriculum Fidelity: A Path Analysis Model. International Journal of Contemporary Educational Research, 8, 130-143.

Bal-Taştan, S., Davoudi, S. M. M., Masalimova, A. R., Bersanov, A. S., Kurbanov, R. A., Boiarchuk, A. V., \& Pavlushin, A. A. (2018). The Impacts of Teacher's Efficacy and Motivation on Student's Academic Achievement in Science Education among Secondary and High School Students. Eurasia Journal of Mathematics, Science and Technology Education, 14, 2353-2366.

Bandura, A. (1977). Self-Efficacy: Toward a Unifying Theory of Behavioural Change. Psychological Review, 84, 191-215. https://doi.org/10.1037/0033-295X.84.2.191

Bandura, A. (1994). Self-Efficacy. In V. S. Ramachaudran (Ed.), Encyclopedia of Human Behavior (Vol. 4, pp. 71-81). New York: Academic Press.

Bandura, A. (2002). Social Cognitive Theory in Cultural Context. Applied Psychology, 51, 269-290. https://doi.org/10.1111/1464-0597.00092

Barni, D., Danioni, F., \& Benevene, P. (2019). Teachers' Self-Efficacy: The Role of Personal Values and Motivations for Teaching. Frontiers in Psychology, 10, Article No. 1645. https://doi.org/10.3389/fpsyg.2019.01645

Cayirdag, N. (2017). Creativity Fostering Teaching: Impact of Creative Self-Efficacy and Teacher Efficacy. Educational Sciences: Theory \& Practice, 17, 1959-1975.

Chen, C. H., \& Yang, Y. C. (2019). Revisiting the Effects of Project-Based Learning on Students' Academic Achievement: A Meta-Analysis Investigating Moderators. Educational Research Review, 26, 71-81. https://doi.org/10.1016/j.edurev.2018.11.001

Creswell, J. W. (2012). Research Design: Quantitative and Qualitative Approaches. Thousand Oakes: Sage Publication.

Creswell, J. W. (2014). Educational Research: Planning, Conducting, and Evaluating Quantitative and Qualitative Research (4th ed.). Boston: Pearson Education, Inc.

Dari, B. U., \& Putro, N. H. P. S. (2021). Correlation between Self-Efficacy and Motivation of English Teachers, towards Students' Achievement in Yogyakarta, Indonesia. Jurnal Pendidikan Progresif, 11, 77-87. https://doi.org/10.23960/jpp.v11.i1.202107 
Gkolia, A., Belias, D., \& Koustelios, A. (2014). Teacher's Job Satisfaction and Self-Efficacy: A Review. European Scientific Journal, 10, 321-342.

Gul, E. (2014). Efficacy of Skill Development Techniques: Empirical Evidence. Journal of Education and Educational Development, 1, 134-144.

Hashim, H. U., Yunus, M. M., \& Hashim, H. (2018). Language Learning Strategies Used by Adult Learners of Teaching English as a Second Language (TESL). TESOL International Journal, 13, 39-48.

Katz, S., Dack, L. A., Malloy, J. P., \& Ontario Principals' Council. (2018). The Intelligent, Responsive Leader. Corwin. https://doi.org/10.4135/9781506386867

Kim, K. R., \& Seo, E. H. (2018). The Difference in the Effect of Academic and Affective Attributes on Academic Achievement Depending on the Level of Depression. Korean Association for Learner-Centered Curriculum and Instruction, 18, 237-257. https://doi.org/10.22251/jlcci.2018.18.21.237

Li, M. J., Liu, Y., Liu, L., \& Wang, Z. H. (2017). Proactive Personality and Innovative Work Behavior: the Mediating Effects of Affective States and Creative Self-Efficacy in Teachers. Current Psychology, 36, 697-706. https://doi.org/10.1007/s12144-016-9457-8

Lim, C. K., Eng, L. S., Mohamed, A. R., \& Ismail, S. A. M. M. (2018). Relooking at the ESL Reading Comprehension Assessment for Malaysian Primary Schools. English Language Teaching, 11, 146-157.

Mahasneh, A. M., \& Alwan, A. F. (2018). The Effect of Project-Based Learning on Student Teacher Self-efficacy and Achievement. International Journal of Instruction, 11, 511-524.

Mahler, D., Großschedl, J., \& Harms, U. (2018). Does Motivation Matter?-The Relationship between Teachers' Self-Efficacy and Enthusiasm and Students' Performance. PLoS ONE, 13, e0207252. https://doi.org/10.1371/journal.pone.0207252

Ministry of Education Malaysia (2015). Malaysian Education Blueprint 2013-2025.

Mohaideen, M. S. H., Ismail, H. H., \& Ab Rashid, R. (2020). The Use of Local Literary Texts as Reading Materials in English Language Classrooms: An Analysis of Teachers' Perspectives. International Journal of Learning, Teaching and Educational Research, 19, 127-144. https://doi.org/10.26803/ijlter.19.11.8

Rajendran, T., Naaim, N. A. B., \& Yunus, M. M. (2019). Pupils' Motivation and Perceptions towards Learning English Using Quizvaganza. International Journal of Scientific and Research Publications, 9, 220-227. https://doi.org/10.29322/IJSRP.9.01.2019.p8529

Sani, S., \& Ismail, H. (2021) Assessing the Use of Learning Strategies among Young Malaysian English as Second Language Learners. Creative Education, 12, 2124-2145. https://doi.org/10.4236/ce.2021.129163

Shahzad, K., \& Naureen, S. (2017). Impact of Teacher Self-Efficacy on Secondary School Students' Academic Achievement. Journal of Education and Educational Development, 4, 48-72.

Sidhu, G. K., Kaur, S., \& Chi, L. J. (2018). CEFR-Aligned School-Based Assessment in the Malaysian Primary ESL Classroom. Indonesian Journal of Applied Linguistics, 8, 452-463.

Tschannen-Moran, M., \& Hoy, A. W. (2001). Teacher Efficacy: Capturing an Elusive Construct. Teaching and Teacher Education, 17, 783-805. https://doi.org/10.1016/S0742-051X(01)00036-1

Tschannen-Moran, M., Hoy, A. W., \& Hoy, W. K. (1998). Teacher Efficacy: Its Meaning and Measure. Review of Educational Research, 68, 202-248. https://doi.org/10.3102/00346543068002202 